\title{
perifèria
}

Número 15, diciembre 2011

www.periferia.name

\section{El olvido del rito. Notas críticas sobre los estudios del pentecostalismo latinoamericano ${ }^{1}$}

\author{
Wilson Muñoz Henríquez - Becario UNESCO. \\ Grup de Investigacions en Sociologia de la Religiò (ISOR). \\ Universitat Autònoma de Barcelona²
}

\begin{abstract}
Resumen
El pentecostalismo es uno de los movimientos cristianos más exitosos y distintivos de Latinoamérica. Durante las últimas décadas se han incrementado significativamente los estudios que han abordado sus más diversas manifestaciones. Sin embargo, uno de los aspectos centrales y característicos del movimiento ha sido ignorado: su dimensión ritual. Mi objetivo es mostrar que esta desatención está relacionada con el predominio de una perspectiva analítica que ha sido reproducida acríticamente en los estudios: las teorías de la acción. Para ello, paso revista a las principales investigaciones realizadas en este área y posteriormente esbozo una crítica de sus presupuestos teóricos, evidenciando sus limitaciones para comprender el fenómeno ritual. Finalmente, sugiero optar por una perspectiva que haga hincapié en la naturaleza interaccional y comunicacional del rito pentecostal parar superar esta falencia.
\end{abstract}

Palabras clave: pentecostalismo, teoría de la acción, ritual, comunicación, Latinoamérica.

\begin{abstract}
Pentecostalism is one of the most thriving and distinctive Christian movements in Latin America. In last decades the studies that address this issue and its
\end{abstract}

1 Este artículo se basa parcialmente en la tesina de Master en Investigación Etnográfica, Teoría Antropológica y Relaciones Interculturales del autor; titulada: "Las manifestaciones del Espíritu. Formas de comunicación con lo sagrado desarrolladas por pentecostales latinoamericanos en Canovelles (Barcelona)", defendida en julio de 2010 en la Universitat Autónoma de Barcelona. Este trabajo fue desarrollado gracias al Programa CONICYT - Becas Chile.

${ }^{2}$ Enviar correspondencia a: wilsonsocio@gmail.com 


\section{perifèria}

Número 15, diciembre 2011

www.periferia.name

different expressions have increased. However, one central and fundamental aspect of this movement has been ignored: its ritual dimension. I want to show that this situation is related to the prominence of an analytical perspective that has been reproduced uncritically in these studies, the so-called "theories of action". For this reason, I study the main researches developed in this area. Then, I cast doubt on the theoretical assumptions of this perspective to shed light on its limits to grasp the ritual phenomenon. Finally, I suggest a view that stresses the interactional and communicative characteristics of the Pentecostal ritual to deal with this insufficiency.

Key words: Pentecostalism, Action theory, ritual, communication, Latin America.

\section{Introducción}

El pentecostalismo es el movimiento religioso que ha crecido con mayor rapidez a lo largo del siglo XX. Su magnitud es tal que luego de su emergencia y futuro desarrollo el cristianismo jamás volverá a ser el mismo, marcando con ello un hito histórico (Anderson 2007: 325). Convertido durante las últimas décadas en el ala más dinámica del cristianismo, actualmente está presente en casi todos los rincones del mundo (Robbins 2004).

No obstante, su presencia es especialmente destacada en Latinoamérica: el gran centro de cristiandad pentecostal, donde su expansión ha sido exponencial ${ }^{3}$. Su importancia en la región es tal que algunos autores se refieren al pentecostalismo como un movimiento religioso típicamente latinoamericano (Casanova 2004: 79). De hecho, la gran influencia que ha ejercido ha sido advertida al constatar cómo otros movimientos cristianos que han tenido relativo éxito en la región, han tendido a pentecostalizarse durante las últimas décadas para sobrevivir al declive del cristianismo tradicional (Bastian 2006a; Gooren 2010; Maduro 2010).

\footnotetext{
${ }^{3}$ Aunque los datos son imprecisos y varían según la fuente considerada, las cifras conservadoras de los estadísticos Barret y Jonson señalan que entre pentecostales, carismáticos y neo-pentecostales, sumaban más de 141 millones de creyentes en América Latina en el año 2000 (Barret \& Jonson 2003; citado en Anderson 2007: 83).
} 


\section{perifèria}

Número 15, diciembre 2011

www.periferia.name

En consonancia con su creciente éxito, en la década de los noventa hubo un auge de estudios sobre el pentecostalismo latinoamericano. Después del predominio de las explicaciones macro-estructurales predominantes desde la década de los sesenta, en este nuevo periodo los investigadores se volcaron hacia las más diversas facetas del movimiento, pero utilizando esta vez explicaciones contextuales basadas en teorías de alcance medio (según la expresión de Merton). Si bien se han producido importantes aportes desde entonces, el predominio de ciertas temáticas ha tenido como correlato la desatención del pentecostalismo como fenómeno religioso "en sí mismo". Esto se aprecia de manera ejemplar en el poco interés que ha recibido uno de los aspectos centrales y distintivos de este movimiento a nivel global: su diversa, frecuente e intensa vida ritual.

Mi objetivo es mostrar que esta desatención no se basa única ni directamente en que exista una predilección por ciertos temas en las investigaciones, sino más bien en el predominio de las denominadas "teorías de la acción" utilizadas a la hora de comprender el pentecostalismo. Sostengo que esta perspectiva generalmente ha ignorado la esfera ritual y, cuando la ha considerado (muy escasamente), no ha realizado una adecuada interpretación de sus características e importancia debido a la limitación de sus presupuestos. Por ello, concluyo que la naturaleza del fenómeno ritual sólo podrá ser comprendida adecuadamente si optamos por cambiar tales presupuestos teóricos, adoptando por una perspectiva que sea sensible con la naturaleza interaccional y comunicacional del rito como fenómeno religioso.

Para ello, mostraré sintéticamente cuáles han sido los estudios más relevantes sobre el pentecostalismo latinoamericano, distinguiendo una primera etapa caracterizada por el predominio de teorías macro-estructurales (1); de una segunda etapa caracterizada por el giro dado hacia temáticas más específicas, centradas en explicar el comportamiento social basándose en las teorías de la acción (2). En función de esta exposición, analizaré críticamente los presupuestos teóricos de este enfoque predominante, destacando las limitantes que poseen estas teorías para comprender la naturaleza del rito (3). Posteriormente, señalaré algunos aspectos conceptuales que serían útiles para abordar el rito pentecostal como un fenómeno religioso de naturaleza comunicacional (4); y finalmente, a modo de conclusión, 


\section{perifèria}

Número 15, diciembre 2011

www.periferia.name

realizaré una breve síntesis de mi argumentación y abriré una pregunta de investigación para futuros desarrollos en esta línea.

\section{Teorías macro-estructurales}

En la década de los sesenta, antes de que se realizaran estudios sistemáticos sobre el creciente desarrollo del pentecostalismo, en Latinoamérica reinaba la explicación marxista sobre la religión (Bastian 2008: 3). Su propuesta explicaba el nacimiento y desarrollo del pentecostalismo bajo la tesis de la conspiración protestante del siglo XIX, reforzada y renovada por la idea de la amenaza imperialista norteamericana que manipulaba grupos religiosos foráneos. Se trataba de una explicación estructural que hacía hincapié en las variables exógenas, dejando al margen la pregunta sobre el porqué se originaban y reproducían tales prácticas y creencias religiosas en la población popular de manera pormenorizada.

En este contexto, los sociólogos Christian D’Espinay y Emilio Willems irrumpieron con investigaciones sistemáticas sobre el pentecostalismo latinoamericano, sentando un precedente a nivel global (Soneira 1991; Guerrero 1994; Bastian 2008; Bergunder 2009). Ellos establecieron una pregunta que acompañó a los estudios macro-estructurales hasta la década de los noventa: comprender las razones del éxito del movimiento. Ambos autores compartían la idea de que el auge del pentecostalismo se debía a una acelerada modernización de la región, aunque llegaban a conclusiones contrapuestas a la hora de caracterizar su rol al respecto.

Según D’Espinay (2009), el crecimiento del pentecostalismo durante la década de los años sesenta estaría vinculado a un proceso de profundas transformaciones sociales producidas en Chile y en Latinoamérica en general, el cual afectó sobre todo a las clases populares que habrían sido víctimas de la migración campociudad, generando con ello importantes manifestaciones de anomia social. En este escenario, el pentecostalismo se habría desarrollado para cumplir una función social específica: ofrecer a los grupos sociales marginados una comunidad de "refugio", caracterizada por propiciar relaciones personales y de dependencia que reproducían el modelo de organización hacendal tradicional. En términos más concretos, las 


\section{perifèria}

Número 15, diciembre 2011

www.periferia.name

prácticas cúlticas desarrolladas en el seno de la comunidad tenían una doble fuente: si bien derivaban de la impronta misionera protestante en la región, eran readaptadas por la tradición popular para responder a la crisis social, difiriendo en algunos aspectos con sus símiles anglosajones. A través de estas prácticas la comunidad operaba de manera liberadora, convirtiéndose así en "el lenguaje de aquellos que no tienen lenguaje" (D’Espinay 2009: 97), la masa desposeída. Con todo, la referencia a estas prácticas es mínima en su obra.

Por su parte, el sociólogo norteamericano Emilio Willems estudió la función social del protestantismo en Brasil y Chile durante el periodo de grandes transformaciones socio-estructurales que vivieron ambos países entre los años cuarenta y cincuenta. Ante una problemática similar, y relacionando también pentecostalismo y modernización, llegó a una conclusión distinta. Para Willems, el pentecostalismo sería un típico representante del protestantismo anglosajón, cuya organización ofrecía la posibilidad de desarrollar un creciente proceso de racionalización, tanto a nivel organizacional como en las prácticas (sobre todo éticas) que desarrollaban sus adeptos. Esto estaría acorde con la creciente modernización que afectaba a las zonas urbanas latinoamericanas. Así, el pentecostalismo ofrecía una respuesta ante la anomia social generada, facilitando la pertenencia a una comunidad de hermanos, pero estimulando a su vez el acelerado proceso de modernización y (supuesta) racionalización (Silveira 2009).

Después de décadas de ausencia de investigaciones sistemáticas sobre el pentecostalismo ${ }^{4}$, en el año 1990 hubo un auge en los estudios, en paralelo al repunte de la tasa de crecimiento del movimiento en la región (Martin 1991: 41). Se volvieron centrales las obras del antropólogo norteamericano David Stoll (1990) y sobre todo del sociólogo británico David Martin (1990). Con nuevos ropajes teóricos, se repetía la antigua sentencia: el éxito del pentecostalismo se asociaba al proceso de modernización latinoamericana, aunque con hincapiés distintos.

\footnotetext{
${ }^{4}$ Importantes excepciones fueron los estudios de Teenekes (1985) y Rolim (1985). Al respecto, véase: Guerrero (1994).
} 


\section{perifèria}

Número 15, diciembre 2011

www.periferia.name

A partir de una etnografía realizada en Guatemala, Stoll concluía que el pentecostalismo en general era una organización políticamente conservadora. Puesto en términos funcionales, se trataba de un vehículo de supervivencia ante el acelerado resquebrajamiento de la organización social tradicional, donde sus creencias y prácticas buscaban expresar las problemáticas y esperanzas de la población desaventajada (Stoll 1990: 392-393).

Mientras que para Martin el crecimiento del pentecostalismo sería análogo a la irrupción del protestantismo durante la transición europea hacia el capitalismo, el cual promovió crecientemente la autonomización y adaptación de los sujetos a las formas individualistas, mercantiles y democráticas propias de la modernidad. América Latina parecía estar volviéndose protestante. Bajo esta perspectiva, el autor optó por destacar más bien las transformaciones producidas en amplias esferas sociales (familia, educación, economía, etc.) y en la ética de los creyentes, infravalorando la dimensión ritual.

Luego de esta breve síntesis, se aprecia que en esta primera etapa de estudios sobre el pentecostalismo latinoamericano se privilegiaron estudios que entregaban explicaciones macro-estructurales de marcado carácter sociológico y que tendían a privilegiar el desarrollo de una explicación funcional para entender su éxito. Utilizando la clásica distinción entre estructura/acción, se puede decir que estas reflexiones teóricas desarrollaban sus explicaciones primordialmente en el nivel de la estructura, para luego descender a la acción: el contexto social se caracteriza por atravesar importantes transformaciones en diversos ámbitos estructurales, lo que impacta en las acciones de los actores involucrados. No es de extrañar entonces que un ámbito tan poco tratado como el ritual, cuando era brevemente mencionado, era entendido como una mera manifestación de o reacción ante las transformaciones estructurales, centrando la fuerza explicativa en este último nivel.

Según Bergunder, las debilidades de los principios explicativos macro-teóricos propios de esta primera etapa, pueden verse claramente ejemplificadas en la obra de Martin, donde el movimiento pentecostal se desvanece en la abstracción, pues se trata de una mera manifestación del protestantismo que podía entenderse a la luz de una explicación estructural. Por ello, "el valor heurístico de este punto de 


\section{perifèria}

Número 15, diciembre 2011

www.periferia.name

vista, que escasamente se relaciona con el objeto de estudio, se vuelve así cuestionable" (Bergunder 2009: 10).

Esta apreciación se encuentra en concordancia con el revisionismo vertido sobre esta primera etapa de producción de estudios, y de manera más especial con la crítica recepción de la controvertida obra de Martin. Muchos científicos sociales jóvenes se mostraron inconformes con la generalidad de este tipo de propuestas, pero especialmente con la relevancia que habían adquirido como fuentes explicativas dentro de la academia. La crítica más corrosiva apuntaba hacia la utilización acrítica de presupuestos etnocéntricos a la hora de iluminar este fenómeno latinoamericano (Míguez 1998; Semán 1998). Más allá de la veracidad de esta crítica, se trataba de una muestra sintomática del vuelco que adquirirían los estudios sobre el pentecostalismo latinoamericano desde entonces y que puede leerse también en otros campos de las ciencias sociales ${ }^{5}$.

\section{Comportamiento social y teoría de la acción}

A partir de la década de 1990 se generó un importante giro en estos estudios a nivel temático y teórico. Se privilegió esta vez el desarrollo de estudios contextuales que exploraban aspectos particulares del pentecostalismo. Esto se enmarcó dentro del nuevo interés por las teorías de alcance medio, especialmente dentro de la sociología. En términos teóricos, este viraje se caracterizó por la adopción de una perspectiva que podríamos denominar ampliamente "teoría de la acción", cuyo distintivo analítico es otorgarle especial atención a los motivos de las actuaciones sociales de los actores. Así, en la mayoría de los estudios, además de las contextualizaciones socio-históricas concretas que se realizaban, se volvía

\footnotetext{
${ }^{5}$ Después de un predominio global en las ciencias sociales de explicaciones estructurales, los estudios han pasado en las últimas décadas a destacar la agencia de los actores en los procesos sociales. Esta última se autocomprende como una alternativa ante la explicación estructural determinista (que dejaba poco espacio para la libertad individual), en tanto hace hincapié en las múltiples estrategias que pueden desplegar contextualmente los actores (Ortner 1984).
} 


\section{perifèria}

Número 15, diciembre 2011

www.periferia.name

especialmente relevante la propia visión del actor social y se destacaba su capacidad de agencia. En este sentido, las peculiaridades del comportamiento social de los pentecostales y sus resortes intencionales se expandieron como fuentes explicativas de la reproducción de diversas áreas de la vida social del movimiento. Desde entonces, la renombrada agencia es la invitada de honor.

La producción de literatura científica de esta segunda etapa sigue en curso y sería imposible de reproducir aquí. No obstante, mencionaré algunas de las principales esferas temáticas abordadas, con el doble fin de dar una visión general de los principales intereses en ésta área y apuntar los lineamientos teóricos que han acompañado a los estudios más significativos.

\subsection{Política}

Uno de los temas más investigados ha sido las relaciones establecidas entre el pentecostalismo y las instituciones políticas, entendidas estas últimas como esferas especializadas en la gestión del poder. Inicialmente se extendió la tesis de D’Espinay (2009), según la cual los actores pentecostales se mantendrían al margen de procesos de mayor participación política, optando por refugiarse en la comunidad y generando con ello una especie de huelga social. Sin embargo, según algunos autores, en las últimas décadas este movimiento habría alcanzado mayor visibilidad como actor político, pasando a interesarse por los sucesos de "este mundo" (Bergues 2008: 225). Habrían proliferado partidos políticos de raíz evangélica, así como actores pentecostales que acceden a otros puestos de liderazgo político y social en la región (Córdoba 2003: 194).

Especial atención ha recibido la creciente representatividad que esta iglesia ha tenido frente al Estado. Un buen ejemplo son los estudios de caso de Wynarczyk (2003; 2006) en Argentina. A partir del análisis de las estrategias que el movimiento desarrolló con actores del campo político, el autor concluye que el pentecostalismo argentino se ha embarcado en una lucha para alcanzar una mayor representatividad como minoría religiosa. De manera similar, las relaciones entre el pentecostalismo y el Estado han sido apreciadas en México (Bastian 1990; 2006a; 2008; Vallverdú 2005), Guatemala (Stoll 1990; Cantón 1998; Steigenga 2005) y 


\section{perifèria}

Número 15, diciembre 2011

www.periferia.name

Brasil (Pedro 2003), corroborando en mayor o menor medida esta tesis.

Otros autores han matizado esta argumentación señalando que la vinculación entre el pentecostalismo y las organizaciones políticas sigue siendo muy débil. En general, sostienen que estos actores han desplazado su participación hacia áreas más comunitarias y mantienen distancia respecto al campo político, dejando intocados temas referidos a las transformaciones estructurales de la sociedad. Al respecto, Fediakova (2002a; 2002) ha observado que mientras el pentecostalismo tradicional tendía a realizar una participación política más activa en Chile, las nuevas formas de pentecostalismo pretenden ejercer los cambios sociales desde niveles más comunitarios e incluso privados. Por lo tanto, seguiría siendo un movimiento despolitizado en el sentido clásico del término, pues no se involucraría en temas nacionales relevantes, sino más bien en asuntos corporativos particulares (Parker y Fediakova 2009). En esta línea, también Míguez (2001) ha destacado la pasividad política del pentecostalismo argentino y Riviére (2007) ha señalado que en Bolivia se trataría de un movimiento poco comprometido políticamente, pese a las protestas simbólicas presentes en su semántica.

\subsection{Conversión e identidad}

El pentecostalismo es un movimiento religioso de marcado carácter conversionista. Este asunto está siendo crecientemente investigado. Por un lado, están los estudios interesados principalmente en las condiciones sociales que han favorecido el proceso de conversión, advirtiendo luego el impacto que ello ha tenido concretamente en los creyentes pentecostales. En esta línea, Míguez (2001) ha intentado explicar el crecimiento del pentecostalismo argentino en función de la crisis económica que atravesó el país en la década de los ochenta, trazando paralelos con casos como Chile, Guatemala y Brasil. Luego de analizar diversas acciones particulares llevadas a cabo por los pentecostales ante esta crisis, concluye que la conversión al pentecostalismo fue realmente una "estrategia de superviviencia" (Míguez 2001: 74), tanto emocional como material, que los actores generaron ante la situación de crisis.

Por otro lado, algunas investigaciones han analizado el fenómeno de la conversión a 


\section{perifèria}

Número 15, diciembre 2011

www.periferia.name

partir de los testimonios generados por los propios conversos sobre este hecho. Así, para Espinar (2003), el pentecostalismo se caracterizaría por reproducir una tradición oral, donde los testimonios de conversión poseen un lugar central en las liturgias. Por ello, su análisis narrativo hace hincapié en la agencia, intencionalidad y creatividad de los testimonios de los conversos. Sus discursos darían cuenta de su propia identidad como proceso dialógico en el cual se manifiesta la transformación personal (Espinar 2003:9). Por su parte, Lucena (2008) ha analizado una serie de testimonios de conversión que algunos programas pentecostales despliegan en diferentes medios de comunicación masiva, concluyendo que tanto la estructura como el contenido de los mismos incitan a la emocionalidad (manipulación) para lograr efectos en la audiencia.

La identidad también es uno de los fenómenos más mencionados en los análisis sobre el pentecostalismo, generando importantes controversias en los últimos años (Cervantes-Ortiz 2003). Sin embargo, pocas veces ha sido profundizado. En general, se ha sostenido que la identidad del pentecostalismo se caracteriza por la centralidad que adquiere el Espíritu Santo y sus manifestaciones, a diferencia de otros movimientos religiosos ${ }^{6}$. A través de estudios de casos, diversas investigaciones han mostrado cómo aspectos específicos de estas manifestaciones contribuyen a reforzar la identidad pentecostal, tanto a nivel individual como grupal. Por ejemplo, evidenciando la importancia de los discursos de sanación en la construcción de la colectividad (Algranti 2008), o el uso de la glosolalia (hablar en lenguas) como estrategia distintiva del movimiento (Garma 2000). Sin embargo, la creciente influencia del pentecostalismo también ha logrado que otros movimientos religiosos adopten algunas de sus prácticas. Barrera (2004) ha evidenciado esta influencia al mostrar cómo ciertas iglesias protestantes en Sao Paulo (Brasil) y Lima (Perú) han reconfigurado la estructura de sus liturgias y crecientemente han incorporado una mayor manifestación de la emocionalidad. Por su parte, en un sugerente artículo, Míguez realizó una comparación entre instituciones seculares y

\footnotetext{
${ }^{6}$ Esta apreciación se debe matizar debido al claro paralelo que posee con el movimiento carismático católico, al parecer influenciado por el pentecostalismo.
} 


\section{perifèria}

Número 15, diciembre 2011

www.periferia.name

pentecostales dentro de recintos penitenciarios argentinos, destacando la mayor efectividad de la organización pentecostal en los procesos de rehabilitación y reinserción social, básicamente porque es un movimiento transformador de la identidad. Se trataría de un colectivo al que cada actor se adhiere voluntariamente, donde se integran ritos religiosos de incorporación a la colectividad y que generaría importantes procesos de encapsulamiento social (Míguez 2000: 58).

\subsection{Indígenas}

Hace tres décadas atrás, una crítica común alzada dentro del círculo de estudiosos del pentecostalismo subrayaba la poca atención que había recibido la presencia de este movimiento religioso en la población indígena. Sin embargo, paulatinamente diversos investigadores se han volcado sobre este tema, en paralelo al importante crecimiento que ha tenido el número de fieles pentecostales indígenas en Latinoamérica.

Este relativo éxito ha sido uno de los principales focos de interés. Una de las líneas explicativas al respecto la encarna la tesis de Giménez (1989), quien argumenta que las "sectas" pentecostales tendrían una buena acogida entre poblaciones indígenas y campesinas fundamentalmente porque constituyen nuevas formas de "religiosidad popular", aunque más adaptadas a los procesos de modernización y a la crisis económica de la sociedad rural asociada. De todas formas, existiría una especie de continuidad estructural entre la religiosidad popular y el pentecostalismo. Ambas se destacarían por su heteronomía, la resistencia a una sistematización intelectual de sus creencias, una orientación pragmática, la búsqueda de lo maravilloso, el emocionalismo intenso y, finalmente, una esperanza utópico milenarista en situaciones de extrema opresión y crisis (Giménez 1989: 128).

Posteriormente ha sido Bastian (2006a; 2006b) quien ha desarrollado y afinado más esta tesis sobre el éxito pentecostal. Por un lado, sostiene el historiador, la adopción del pentecostalismo representa una ruptura (protesta) con la comunidad católica tradicional que sostiene la doble tutela de los caciques locales y las iniciativas estatales, facilitando con ello el desarrollo de una relativa autonomía 


\section{perifèria}

Número 15, diciembre 2011

www.periferia.name

para la reivindicación política indígena; tesis sostenida también por otros autores para el caso de movimientos indígenas en Ecuador (Andrade 2005) y en Colombia (Demera 2003). Por otro lado, la adquisición de nuevas formas de religiosidad aparentemente exógenas, como el pentecostalismo, pueden responder a una larga tradición de adaptación y resistencia por parte de las comunidades étnicas, siendo más flexibles al respecto (Bastian 2006b: 42-43). Finalmente, pese a que el pentecostalismo es un movimiento de origen norteamericano, Bastian recalca que se manifestó en la región como un fenómeno endógeno y propiamente latinoamericano a través del desarrollo de algunas prácticas que fueron centrales en su expresión religiosa y que estaban ya presentes en la tradición popular, sobre todo en las poblaciones indígenas, como son la glosolalia (hablar en lenguas), la taumaturgia (sanación) o los exorcismos (Bastian 2006a: 46). En cierta forma, esta tesis de la continuidad cultural del pentecostalismo también ha sido evidenciada en otros casos, como la población mapuche en Chile (Foerster 1993) o los toba en Argentina (Wright 1992).

Sin embargo, a partir de estudios de caso distintos y con utillajes conceptuales autoentendidos como críticos, algunas investigaciones han destacado los conflictos que se han producido entre ambos grupos sociales, remarcando la presencia de procesos de aculturación generados por la impronta pentecostal. De este estilo ha sido el acercamiento que tanto Van Kessel como Guerrero han tenido con el pentecostalismo aymara en el altiplano chileno. Ambos han señalado que desde la década de los setenta hasta los noventa, el explosivo crecimiento del movimiento en la población aymara del norte de Chile estuvo acompañado por profundos conflictos, debido a que la conversión al pentecostalismo pasaba por la negación de creencias y prácticas arraigados en la población aymara (Guerrero y Van Kessel 1990). Esta lucha ideológica se trasladó a todas las esferas sociales, alcanzado a la prensa local, los pleitos jurídicos y desatando incluso luchas iconoclastas (Guerrero 1997).

\subsection{Rol de la mujer}

Gracias a diversos estudios de carácter antropológico y la presencia de perspectivas feministas en los análisis de los últimos años, las transformaciones del rol de la 


\section{perifèria}

Número 15, diciembre 2011

www.periferia.name

mujer y de los imaginarios sociales asociados a ella en el pentecostalismo se han vuelto temáticas relevantes ${ }^{7}$.

Brusco (1995; citado en Bergunder 2009: 10) ha mostrado que en el caso colombiano, si bien las mujeres no acceden en general a altos cargos eclesiásticos, disponen de círculos femeninos muy activos que operan en paralelo con las organizaciones más formales. Agrega que las transformaciones mayores afectan al ámbito del hogar pentecostal, pues cuando en una pareja ambos son conversos, el marido suele dejar muchas costumbres machistas y tiende a fomentar prácticas de respeto hacia la mujer. Desde una perspectiva feminista, Brusco asegura que se trata de una clara forma de emancipación femenina. Con ciertos matices, esta tesis ha sido corroborada por diversas autoras y autores en la región (Montecino 2002; Algranti 2007; Pérez 2009; Linhardt 2009).

Sin embargo, también se ha observado que transformaciones como las señaladas no implican necesariamente la mutación de las desiguales relaciones de género establecidas. Al parecer, se reproducirían fácilmente fenómenos de neomachismo, favoreciendo muchas veces que los hombres detenten un poder arbitrario, pese a que las mujeres pentecostales utilicen la retórica de la igualdad en clave cristiana (Montecino 2002). Tarducci (2005), analizando el caso de pastoras pentecostales argentinas, avanza más en este sentido y cuestiona fuertemente el supuesto acceso igualitario que el pentecostalismo declara, insistiendo en que existen importantes diferencias de género que desalientan o prohíben la participación de pastoras en asuntos eclesiales.

En términos genéricos, Algranti (2007) afirma que los estudios de género sobre la mujer en el pentecostalismo latinoamericano llegan a una situación paradójica. Si

\footnotetext{
7 Esto es especialmente interesante porque Motley, basándose en estimaciones realizadas por Harvey Cox en la década de los noventa, ha señalado que las mujeres representarían cerca de dos tercios de los creyentes pentecostales a nivel mundial. La autora refuerza esta estimación a nivel latinoamericano señalando las estadísticas de la proporción de mujeres obtenidas por Bowen para México (64\% para el año 1996) y por Brusco en Guatemala (64\% para el año 1993) (Motley 2003: 171).
} 


\section{perifèria}

Número 15, diciembre 2011

www.periferia.name

bien el movimiento trastoca parcialmente las estructuras culturales de dominación, simultáneamente se erige un escenario donde se vuelven a reproducir estas diferencias. Por ello, existe "la dificultad de pensar un fenómeno que en cierta medida contribuye a los intereses prácticos y estratégicos de las mujeres en términos de emancipación de las estructuras patriarcales, a la vez que restaura la sociodicea de la dominación masculina frente a la crisis de las instituciones que la sustentaban" (Algranti 2007: 186).

\section{Consideraciones críticas}

Luego de esta breve panorámica realizada sobre los principales ámbitos temáticos abordados por los estudios sobre el pentecostalismo latinoamericano, me gustaría hacer algunas consideraciones críticas sobre la perspectiva teórica predominante al respecto. Para ello, tomaré como puntal un hecho académico-científico especialmente significativo al respecto.

En una edición especial del Newsletter de la Asociación de Cientistas Sociales del Mercosur (1998), se generó un foro donde destacados investigadores del pentecostalismo latinoamericano reflexionaron sobre el estado de los estudios en este ámbito, y además se les solicitó que propusieran vías de investigaciones futuras. Existía consenso en que el pentecostalismo era uno de los ámbitos más dinámicos de la sociología y antropología de la religión actual. Sin embargo, varios autores declararon abiertamente el riesgo que implicaba no superar algunas prenociones ampliamente utilizadas, así como también temas y explicaciones ya abiertamente instaurados (Semán 1998; Míguez 1998). En un acto de sinceridad intelectual, el sociólogo Daniel Míguez señaló que muchos estudios habían instalado una prenoción altamente imperceptible e incuestionada:

... Esto es que el crecimiento del pentecostalismo efectivamente tendrá algún tipo de impacto relevante sobre la vida política y económica de las sociedades en las que se desarrolla. Casi nadie ha escapado hasta aquí - y en esto me incluyo - a, de alguna manera, discutir las potenciales y encubiertas (porque nunca presentes ni evidentes) repercusiones del pentecostalismo sobre la 


\section{perifèria}

Número 15, diciembre 2011

www.periferia.name

vida económica y política de los países sudamericanos. Pero incluso después de treinta años de discusión, no se hace evidente que los destinos políticos y económicos de los países en que el pentecostalismo ha sido más influyente hubieran sido sustancialmente distintos sin su presencia. Legítimamente, cabe entonces la pregunta de por qué es tan relevante discutir la influencia del pentecostalismo en la política y en la economía si, de hecho, su incidencia en las mismas tiende a cero (Míguez 1998: 2).

El sociólogo argentino agregó que esta predilección temática estaba altamente influenciada por las posturas eurocéntricas que sustentaron los estudios más destacados generados en los años noventa, refiriéndose especialmente con ello a Martin (1990), Stoll (1990) e incluso a Bastian (1990). Sin embargo, aunque el diagnóstico del autor es cierto y su cuestionamiento muy lúcido, su explicación es parcial y requiere de una observación.

En mi opinión, esta predilección temática no es meramente la muestra del eurocentrismo presente a la hora de entender el fenómeno. Más bien creo que está directamente relacionada con la utilización acrítica de los presupuestos teóricos de las teorías de la acción que rigen a la mayoría de estos estudios. Una muestra clara de ello se aprecia en la frecuente utilización (consciente o no) de dos metáforas a la hora de comprender el pentecostalismo: concebirlo inserto en un "mercado religioso" o incrustado en un "campo de poder", ambas propuestas derivadas de las teorías de la acción. Una síntesis de ambas ideas clarificará mi argumento.

La idea de "mercado religioso" ha sido empleada recurrentemente para comprender la creciente diversidad religiosa en Latinoamérica. Son poquísimos los estudios que realmente han discutido en profundidad la adecuación analítica de esta figura conceptual, pero muchísimos los que apelan (acríticamente) a este lugar común en la literatura (Frigeiro 1998). En términos esenciales, esta tesis sostiene que el pentecostalismo habría aparecido en el marco de un monopolio del mercado religioso sostenido por la iglesia católica, la cual controlaba la emisión de bienes simbólicos, de manera que su emergencia habría favorecido una diversificación de la oferta religiosa. En este contexto, las iglesias operarían como oferentes en busca de nuevos creyentes demandantes de sus ofertas religiosas. Firmemente anclados 


\section{perifèria}

Número 15, diciembre 2011

www.periferia.name

en la idea de una supuesta modernidad que acrecienta procesos de individualización y mayor libertad, los creyentes seleccionarían la oferta más apropiada, maximizando su utilidad y permitiéndose incluso cambiar de religión cuando lo estimen conveniente. Se trataría de religiones y elecciones casi "a la carta". De esta forma, las acciones desarrolladas por los pentecostales son vistas como estrategias que satisfacen necesidades determinadas, propiciadas por un escenario crecientemente diverso.

Una segunda imagen, mucho más visitada e invocada que la anterior, es la idea de campo religioso, entendida en el sentido desarrollado por Pierre Bourdieu. Quizás haya sido Bastian (1990) quien más explícitamente se haya adherido a esta propuesta, aunque esta metáfora asoma en incontables estudios. La lógica de la propuesta es la siguiente. La emergencia y desarrollo del pentecostalismo se habría insertado en un campo de fuerzas que atañe a la esfera religiosa, donde los distintos movimientos religiosos y sus actores son entendidos como agentes ubicados en posiciones objetivas estructurantes, las cuales remiten a la jerarquía relativa que poseen en función de su obtención del capital simbólico (la "salvación", principalmente). Los agentes lucharían dentro de este campo motivados por su interés, intentando mejorar sus posiciones y acrecentar su capital religioso. Esta propuesta ha sido utilizada para entender la relación del pentecostalismo con otras esferas sociales, sobre todo con el poder político y el económico; con otras religiones como el catolicismo, aunque también entre las mismas congregaciones pentecostales; y finalmente dentro de las comunidades locales. En general, las acciones concretas de los creyentes son explicadas por la adopción y reproducción de un habitus religioso, desarrollado gracias a la función ideológica de la religión que suele justificar la posición social de los actores.

Sería excesivo atribuir la predilección temática por los ámbitos económico y político, única y exclusivamente al predominio de las teorías de la acción. Pero al menos es innegable lo funcional que resulta analizar estos temas bajo los presupuestos de las dos metáforas o ideas recién señaladas. En el primer caso, se trataría de la teoría que hace más de un siglo propuso Weber, según la cual lo que define a lo social es efectivamente la "acción social". Esta acción sólo puede entenderse en función del 


\section{perifèria}

Número 15, diciembre 2011

www.periferia.name

sentido mentado por los actores, donde son las diversas orientaciones motivacionales lo que permite distinguir su especificidad categorial. En el segundo caso, es cierto que la propuesta de Bourdieu tiene en consideración no sólo las acciones, sino también el campo en el cual se desarrollan. Esta articulación se conjuga dialécticamente en el concepto de habitus, donde las acciones desarrolladas no sólo remiten al sentido mentado del actor, sino también a los intereses (conscientes o no) que están en juego dentro del campo. Sin embargo, siguen siendo los actores (personas, grupos o sistemas) y sus estrategias e intereses en juego los principales puntos de referencia en los análisis aplicados al caso pentecostal.

Mi punto aquí es insistir en que esta predilección teórica está presente no sólo en el tratamiento privilegiado de estas esferas, sino que su "lógica" explicativa se ha extendido al análisis de fenómenos como la conversión religiosa, la identidad, el rol de la mujer o el impacto en los grupos indígenas en el pentecostalismo, como ya mencioné. Todos estos fenómenos suelen ser leídos con las anteojeras de la "acción social": finalmente son los actores (individuales o colectivos) las unidades de análisis y sus motivaciones mentales o intereses los focos de observación y, en mayor o menor medida, también de explicación.

Pero lo más importante es que este predominio temático señalado por Míguez asociado a la predilección teórica por las teorías de la acción, según sostengo -, tiene una consecuencia brutal que se transforma en una deficiencia esencial.

Creo que la concentración en los potenciales impactos políticos y económicos del pentecostalismo ha llevado a descuidar sus posibles repercusiones en el ámbito de lo religioso en sí mismo. ¿Cómo se modifica el campo religioso dado el crecimiento del pentecostalismo? ¿Cómo reaccionan otros actores religiosos frente a él? ¿Cómo se vincula el pentecostalismo con la forma en que los conversos tienen de interpretar sus relaciones con lo sagrado, y en esto con sus maneras de construir sus identidades religiosas? (Míguez 1998: $3)$.

El sociólogo argentino da certeramente en el blanco cuando denuncia la 


\section{perifèria}

Número 15, diciembre 2011

www.periferia.name

desatención que los estudios del pentecostalismo han tenido con el fenómeno religioso "en sí mismo". De igual forma, Allan Anderson (2007), un destacado investigador del pentecostalismo a nivel global, ha afirmado fehacientemente que es muy común que historiadores, antropólogos y sociólogos pasen por alto algo obvio: que el pentecostalismo es eminentemente un fenómeno religioso.

Creo que una manifestación ejemplar de esta debilidad general de los estudios sobre el pentecostalismo es el paradójico descuido de su dimensión ritual. El antropólogo norteamericano Joel Robbins (2009) sostiene que a nivel global, salvo escasas excepciones, el fenómeno del rito pentecostal no ha sido estudiado en profundidad, ni siquiera por una disciplina como la antropología sociocultural cuya sensibilidad y competencia al respecto serían las más adecuadas. Esta observación se agudiza cuando observamos que uno de los consensos existentes en la literatura afirma que el aspecto distintivo de este movimiento es su frecuente, intensa y rica vida ritual. Al parecer, es el rito lo que articula los encuentros semanales en el culto, las sesiones de oración, vigilias, estudios, y muchos otros ámbitos de la vida pentecostal.

Hasta aquí la problemática es clara. No obstante, el paso hacia una propuesta de superación necesita una reflexión crítica de la oferta lanzada por Míguez. De hecho, la falencia planteada podría resolverse fácilmente con una propuesta trivial: dirigir nuestra atención al fenómeno del rito pentecostal y ponernos prontamente "manos a la obra". Sin embargo, si continuamos manteniendo incuestionados los supuestos de la teoría de la acción en el abordaje, podríamos arriesgarnos a no comprender lo distintivo del rito pentecostal, dejando así desatendida nuevamente esta esfera. Me explico.

Quien haya realizado trabajo de campo con congregaciones pentecostales o simplemente esté familiarizado con literatura sobre este movimiento religioso, creo que aceptaría sin mayores dificultades la siguiente observación: las diversas prácticas cúlticas generadas normalmente a lo largo de los encuentros religiosos llevados a cabo por los pentecostales, pueden ser entendidas como formas de comunicación ritual enmarcadas en un contexto claramente interaccional. En general, en estas sesiones se establece una comunicación altamente ritualizada a 


\section{perifèria}

Número 15, diciembre 2011

www.periferia.name

nivel oral y corporal entre los presentes, donde se comunica sobre y con lo sagrado (el Espíritu Santo). Si esto suele ser así, ¿cómo podría entonces una teoría de la acción, empeñada en comprender la acción de los actores principalmente por la vía de sus motivaciones e intereses individuales, capturar la naturaleza interaccionalcomunicacional del rito?

Claramente intentos no han faltado, mas la solución ha sido (quizás) demasiado fácil: leer las prácticas rituales como estrategias de actores, sean estos individuales o colectivos. Sin embargo, a una propuesta como esta se le escapa entre las manos aquello que intenta atrapar, pues las explicaciones no remiten a aquello que es propio del ámbito religioso ritual: la comunicación con lo sagrado. Más bien, repito, remiten finalmente al sentido mentado o los intereses de los actores como base de su explicación. Nos encontramos entonces con un problema cuasi-ontológico, pues lo que parece estar en juego es lo concebido teóricamente como "lo social", y por ende, digno de estudio y fuente de explicación. Es por ello que aunque el cuestionamiento de Míguez es agudo y certero, su oferta es también una abdicación al problema aquí planteado, pues sigue sembrando sus esperanzas demasiado en los actores y en la interpretación de sus acciones, movidos en "campos" o "mercados" religiosos.

\section{Propuesta}

Si el rito es claramente un fenómeno comunicativo de naturaleza interaccional, sería lógico abordarlo utilizando una perspectiva que entienda interaccionalmente a la comunicación y que sea especialmente sensible con los ritos religiosos. En este sentido, creo que la propuesta teórica de Luhmann sobre los sistemas de comunicación en general y los sistemas de interacción en particular, otorga una base conceptual adecuada para entender a la comunicación ritual religiosa como un fenómeno "en sí mismo", además de permitir entablar un diálogo con otras propuestas a fines, como argumentaré muy brevemente.

Luhmann ha puesto a la comunicación en el centro del interés sociológico. Su radicalidad consiste en entenderla como el fenómeno eminentemente social y sui 


\section{perifèria}

Número 15, diciembre 2011

www.periferia.name

generis que permite la reproducción de la sociedad. Con ello intenta romper con la larga tradición que pone al actor y sus acciones en la base de lo social. El autor no niega la existencia ni importancia de las acciones, pero advierte que su vaguedad conceptual y su anclaje en la filosofía del sujeto, impiden comprender el fenómeno realmente emergente que caracteriza a lo social: la comunicación (Luhmann 1998: 140 y ss.). Las acciones sí importan, pero sólo en la medida que jueguen un rol en la reproducción de la comunicación. Es en este sentido que la comunicación (lo social) es emergente, es un nuevo orden de realidad que no puede ser descrito totalmente en función de sus partes constituyentes (sus condiciones de posibilidad), pues posee una autonomía relativa respecto a ellas. Es decir, si bien la comunicación necesita de las acciones (y éstas, a su vez, del sentido mentado de sus actores, aunque no necesariamente), la comunicación y su lógica no se reducen a ellas.

Estos presupuestos teóricos se recogen en la conceptualización que el autor realiza de la comunicación, entendida como la síntesis de tres episodios selectivos entre (al menos) un ego y un alter: 1) selección de la información (qué se comunica), 2) selección de dar-a-conocer la información (cómo se comunica) y 3) selección de comprensión de la comunicación (comprender la comunicación) (Luhmann 1998: 142-143). Lo interesante de la propuesta es que sólo se genera comunicación cuando se sintetizan estas tres selecciones, por lo que cada una de las etapas sólo tiene sentido si se conjugan con las otras selecciones, permitiendo así su reproducción: "la comunicación sólo se genera cuando esta diferencia es observada, exigida, comprendida y puesta como base para la selección de la conducta de enlace" (1998 [1984]: 143). Sólo así pueden nacer cadenas comunicativas.

Lo analíticamente importante es que cada una de estas selecciones sea considerada para comprender el éxito de la comunicación, su reproducción. No basta considerar sólo la información seleccionada en la acción (sentido mentado por los actores), su manifestación, o la comprensión por parte de un actor de estos actos y su diferencia; sino la reproducción de secuencias comunicativas. Esto es lo que permite poner en marcha lo social. Un análisis así debería entender al rito, entonces, como un gran fenómeno comunicativo. Pero se hace necesaria una 


\section{perifèria}

Número 15, diciembre 2011

www.periferia.name

especificación más concreta respecto al tipo de lógica comunicativa que rige al rito.

El rito se genera y reproduce primordialmente en el ámbito de los sistemas de interacción. Estos sistemas necesitan la presencia de al menos dos personas para desarrollarse y su particularidad distintiva es que utilizan la distinción presentes/ausentes para orientar a todas sus comunicaciones. Así, el límite de estos sistemas se determina por todo aquello que pueda ser tratado como físicamente presente en la comunicación y ello permite que se siga reproduciendo (Luhmann 1998: 371). Los participantes realizan sus selecciones tomando en cuenta a los otros presentes, además de considerar que su comportamiento pueda ser interpretado comunicativamente por otros. Esto último se denomina percepción reflexiva (Corsi 1996: 96). En cierta forma, esta percepción reflexiva obliga a la comunicación, pues las personas no pueden evitar que sus comportamientos sean leídos como emisiones comunicativas por otros presentes (Luhmann 2006). Como ha señalado también Goffman, en estos escenarios de interacción "la participación es una obligación vinculante" (Goffman 2006: 360).

Esto se debe a que la corporalidad de los participantes cobra una significancia estratégica en la distribución de relevancias y motivos para la comunicación, en tanto es el centro de atención durante toda comunicación co-presencial. El cuerpo siempre está comunicando. Como señalaba Goffman, es en el ámbito de la interacción donde realmente "se encarna y se da lectura a todas las manifestaciones corporales" (Goffman 1991: 177), de manera que la escenificación cobra mayor importancia en estos encuentros. No es raro entonces que Luhmann, refiriéndose ahora al ámbito religioso, entendiera al rito como una forma peculiar de comunicación religiosa orientada especialmente a la escenificación (Luhmann 2007: 165). En el caso religioso, es necesario escenificar y representar a través de comunicaciones simbólicas aquello que de lo contrario no podría acontecer y que ni siquiera podría ser pensado, ni hablado: lo trascendente. Es en este punto donde aparece lo distintivo de la religión en términos fenomenológicos y pragmáticos para el autor: existe religión siempre que se considere lo inmanente bajo el punto de vista de la trascendencia en la comunicación (Luhmann 2007: 69).

Lo relevante es que el rito se caracterizaría por ser un acto comunicacional que 


\section{perifèria}

Número 15, diciembre 2011

www.periferia.name

maximiza el nivel performativo de la comunicación. No sólo en el sentido de que decir algo es también hacer algo como acto convencional; sino, sobre todo, porque se trata de una ejecución actuada, teatralizada y que utiliza diversos medios para generar una intensificación de la comunicación, cuyo objetivo es propiciar que exista aquella comunicación con una realidad alterna como lo sagrado. Finalmente, es también performativa en tanto implica pragmáticamente a sus participantes a través de la utilización de ciertos marcadores simbólicos asignados a y por los participantes del rito.

Por ahora, creo que estos presupuestos y conceptos teóricos bastan como premisas básicas iniciales para abordar el fenómeno del rito pentecostal de manera adecuada. Una discusión más detallada al respecto se aleja del objetivo y formato de este artículo. Procederé entonces a sintetizar mi argumento principal y plantear algunas preguntas para futuras investigaciones.

\section{Conclusión}

En general, los estudios sobre el pentecostalismo latinoamericano han desatendido un fenómeno central y distintivo del movimiento: su vida ritual. He intentado mostrar que esta deficiencia está relacionada con el predominio incuestionado de las teorías de la acción social en estas investigaciones. Esta perspectiva ha privilegiado el análisis de temas más acordes con su esquema analítico, como son los aspectos económicos o políticos. Sin embargo, no ha intentado comprender al fenómeno religioso "en sí mismo", expresado de manera ejemplar en el rito, pues sus premisas no permiten captar lo distintivo de este asunto. Incluso cuando se ha acercado parcialmente a este ámbito, ha puesto el acento en el sentido mentado o los intereses de los actores, obviando que el rito es una forma de comunicación emergente y distintiva.

Por ello, considero que una perspectiva que entienda la comunicación como fenómeno social sui generis puede comprender mejor la naturaleza interaccional del rito, además de permitir un diálogo con perspectivas complementarias. Una de las ventajas de conceptualizar la comunicación como un acto de triple selección es que 


\section{perifèria}

Número 15, diciembre 2011

www.periferia.name

permite considerar a todas las fases que hacen posible su generación y reproducción, posibilitando una mejor caracterización del fenómeno comunicativo. En el caso del pentecostalismo, son sus peculiares prácticas comunicacionales las que posibilitan la reproducción de sus ritos, y considero que éste es el aspecto distintivo del movimiento. Ahora bien, ¿no resultará justamente esta forma particular de comunicación simbólica con lo divino la clave del éxito del movimiento pentecostal? Esta es una pregunta central para comprender el desarrollo del pentecostalismo latinoamericano y merece el más digno interés científico, sin embargo, queda abierta al desarrollo de futuras investigaciones en esta línea.

\section{Bibliografía}

Algranti, Joaquín (2007). "Tres posiciones de la mujer cristiana. Estudio sobre las relaciones de género en la narrativa maestra del pentecostalismo". Ciências Sociais e Religião, 9 (9), pp. 165-193.

Anderson, Allan (2007 [2004]). El pentecostalismo. El cristianismo carismático global. Madrid: Akal; pp. 325-333.

Andrade, Susana (2005). "El despertar político de los indígenas evangélicos en Ecuador". Iconos, 22, pp. 49-60.

(2006). "Iglesias Evangélicas y Pentecostales Quichuas en la Provincia de Chimborazo. Ecuador". En: Guerrero, Bernardo (et.). De indio a hermano: pentecostalismo indígena en América Latina. Iquique: Ediciones Campvs, Universidad Arturo Prat, pp. 77-110.

Barrera, Paulo (2004). "Domesticación de la razón protestante en el pentecostalismo. Perspectivas sociológicas sobre Perú y Brasil". Presentado en Conferencia: Protestantism in Andean Countries: Historical Perspectivas, LASA 2004, Las Vegas.

Bastian, Jean-Pierre (1990) Historia del protestantismo en América Latina. México: CUPSA. 


\section{perifèria}

Número 15, diciembre 2011

www.periferia.name

(2006a). "De protestantismos históricos a los pentecostalismos Latinoamericanos: Análisis de una mutación religiosa". Revista de Ciencias Sociales (CI), 16, pp. 38-54.

(2006b). "La etnicidad redefinida: pluralización religiosa y diferenciación intraétnica". En: Guerrero, Bernardo (et.). De indio a hermano: pentecostalismo indígena en América Latina. Iquique: Ediciones Campvs, Universidad Arturo Prat, pp. 21-53.

(2008). "En diálogo con la obra de Lalive, d'Epinay. Búsquedas de una sociología histórica del cambio religioso en América Latina". Cultura y Religión, 2 (2), pp. 1-25.

Berges, Juana (2008). "Entre la ortodoxia y los cambios. Un análisis del pentecostalismo en Cuba." En: Aurelio Alonso (comp.). América Latina y el Caribe. Territorios religiosos y desafíos para el diálogo. Buenos Aires: CLACSO.

Bergunder, Michael (2009). "Movimiento pentecostal en América Latina: Teorías sociológicas y debates teológicos". Cultura y Religión, 3 (1), pp. 6-36.

Cantón, Manuela (1998). Bautizados en fuego. Protestantes, discursos de conversión y política en Guatemala, 1989-1993. Antigua-Vermont: Centro de Investigaciones Regionales de Mesoamérica y Plumsock Mesoamerican Studies.

Casanova, José (2004). "Religiones públicas en un mundo global". Entrevista. Debates, 218, pp. 73-86.

Cervantes-Ortiz, Leopoldo (2003). "Protestantismo, protestantismos e identidad en América Latina y México". Graffylia, 2, pp. 125-131

Córdoba, Julio (2003). "Capacidades políticas del movimiento evangélico boliviano". Nuevos Actores Aociales, 1, pp. 193-258.

D’Espinay, Christian (2009 [1968]). El refugio de las masas. Estudio sociológico del protestantismo chileno. Santiago: Universidad de Santiago de Chile - Instituto de Estudios Avanzado USACH - Centro Evangélico de Estudios Pentecostales CEEP. Demera, Juan (2003). "Católicos y protestantes entre los indígenas guambianos. La 


\section{perifèria}

Número 15, diciembre 2011

www.periferia.name

adopción y transformación de nuevas colectividades". Ciências Sociais e Religião, 5 (5), p.173-190.

Espinar, Ángel (2002). "Los discursos de la identidad pentecostal". Disponible en: <http://www.naya.org.ar/congreso2002/ponencias/angel_espinar.htm> [Consulta, 15 mayo 2010].

Fediakova, Evguenia (2002a). "Separatismo o participación política: Evangélicos chilenos frente a la política". Revista de Ciencia Política, 22(2), pp.32-45.

(2002b). "Somos parte de esta sociedad. Evangélicos y política en el Chile post autoritario". Política, 43, pp.253-284.

Foerster, Rolf (1993). "Pentecostalismo mapuche: ¿fin o reformulación de la identidad étnica?". En Introducción a la religiosidad mapuche. Santiago: Editorial Universitaria, pp. 155-163.

Frigeiro, Alejandro (1998). "Desregulación del mercado religioso y expansión de nuevas religiones: Una interpretación desde la oferta". Presentado en Conferencia: Religião e Sociedade no Fim do Milenio: XXII Encontro Anual da ANPOCS. Caxambu, MG - 27-31 de Outubro, 1998.

Garma, Carlos (2000). "La socialización del don de lenguas y la sanación en el pentecostalismo mexicano". Alteridades, 10 (20), pp. 85-92.

Giménez, Gilberto (1989). "Nuevas dimensiones de la cultura popular: las sectas religiosas en México". Estudio sobre las Culturas Contemporáneas, 3 (7), pp-119130.

Goffman, Erving (1991 [1983]). "El orden de la interacción". En Winkin, Yves (ed.). Los momentos y sus hombres. Barcelona: Paidós, pp. 169-205.

(2006 [1974]). Frame analysis: los marcos de la experiencia. Madrid: Centro de Investigaciones Sociológicas; Siglo XXI.

Gooren, Henri (2010). "El pentecostalismo en Guatemala: aportes y debilidades". Presentado en Conferencia: Rostros del protestantismo en Guatemala, Centro Edras. Guatemala, 28-30 de julio, 2009. 


\section{perifèria}

Número 15, diciembre 2011

www.periferia.name

Guerrero, Bernardo (1994). Estudios sobre el Movimiento Pentecostal en América Latina. Cuadernos de Investigación Social no 35, Centro de Investigaciones de la Realidad del Norte. Iquique: Chile.

(1997). "Política y religión en la prensa de Iquique". Revista de Ciencias Sociales (CI), 7, pp. 52-65.

Lindhardt, Martin (2009). "Poder, género y cambio cultural en el pentecostalismo chileno". Cultura y Religión, 3 (2), pp. 1-18.

Lucena, Silvio (2008). "Estructura e implicancias del relato testimonial de conversión en la Iglesia Universal del Reino de Dios". Iberoamérica Global, 3, pp. 78-102.

Luhmann, Niklas (1998 [1984]). Sistemas sociales: lineamientos para una teoría general. Barcelona: Anthropos.

(2006 [1997]). "Interacción y sociedad" en La sociedad de la sociedad. México: Herder - Universidad Iberoamericana, pp. 643-655. (2007 [1997]). La religión de la sociedad. Madrid: Trota.

Maduro, Otto (2009). "Religión y exclusión/marginación. Pentecostalismo globalizado entre los hispanos en Newark, Nueva Jersey." Cultura y Religión, 3(1), pp. 37-54.

Mansilla, Miguel (2008). "Del refugio a la protesta. El refugio de las masas 19682008: A cuarenta años de su publicación". Cultura y Religión, 2(2), s/p.

Martin, David (1990). Tongues of Fire. The Explosion of Protestantism in Latin America. Oxford : Blackwell.

(1991). "Otro tipo de revolución cultural. El protestantismo radical en Latinoamérica". Estudios Públicos, 44 (primavera), pp. 39-62.

Míguez, Daniel (1998). "¿Qué puede agregarse a los clásicos?: Buscando nuevos horizontes a los estudios sobre el Pentecostalismo Latinoamericano". Newsletter de la Asociación de Cientistas Sociales de la Religión en el Mercosur, 6, s/p.

(2000). "Conversiones religiosas, conversiones seculares. Comparando las 


\section{perifèria}

Número 15, diciembre 2011

www.periferia.name

estrategias de transformación de identidad en programas de minoridad e iglesias pentecostales". Ciências Sociais e Religião, 2 (2), pp. 31-62.

(2001). "La conversión religiosa como estrategia de superviviencia. Los pentecostales y el descenso social durante la década perdida". Intersecciones en Antropología, 2, pp. 73-88.

Montecino, Sonia (2002). "Nuevas feminidades y masculinidades: una mirada de género al mundo evangélico de La Pintana". Estudios Públicos, 87, pp. 73-103.

Motley, Anne (2003). "Taking stock and Building Bridges: Feminism, Women's Movements, and Pentecostalism in Latin America". Latin American Research Review, 38 (1), pp. 169-186.

Ortner, Sherry (1984). "Theory in Anthropology since the Sixties". Comparative Studies in Society an History, 26, 1, pp.126-166.

Parker, Cristian y Fediakova, Evguenia (2009). "Evangélicos en Chile Democrático (1990-2008): Radiografía al centésimo aniversario". Cultura y Religión, 3 (2), pp. 48-75.

Pérez, Verónica (2009). "Mujeres y pentecostalismo: Repensando el espacio sagrado, la iglesia". Cultura y Religión, 3(1), pp. 129-138.

Pitarch, Pedro (2003). "Infidelidades indígenas". Revista de Occidente, 270, pp. 60-75.

Rivière, Gilles (2007). "Bolivia: el pentecostalismo en la sociedad aimara del Altiplano". Nuevo Mundo Mundos Nuevos, pp.1-22.

Robbins, Joel (2004). "The globalization of pentecostal and charismatic christianity". Annual Review of Anthropology, 33, 117-143.

Robbins, Joel (2009). "Pentecostal Networks and the Spirit of Globalization. On the Social Productivity of Ritual Forms". Social Analysis, 53 (1), pp. 55-66.

Semán, Pablo (1998). "Para nuevas perspectivas en los estudios sobre el pentecostalismo". Newsletter de la Asociación de Cientistas Sociales de la Religión en el Mercosur, 6, s/p. 


\section{perifèria}

Número 15, diciembre 2011

www.periferia.name

Silveira, Leonildo (2009). "Religión y Modernización. La producción y la recepción de los escritos de Emilio Willems en Brasil sobre religión". Cultura y Religión, 3 (2), pp. 5-25.

Soneira, Jorge (1991). "Estudios sociológicos sobre el pentecostalismo en América Latina". Sociedad y Religión, 8, pp.60-67.

Steigenga, Timothy (2005). "Democracia y el crecimiento del protestantismo evangélico en Guatemala: entendiendo la complejidad política de la religión «pentecostalizada»". América Latina Hoy, 41, pp. 77-97.

Stoll, David (1990). ¿América Latina se vuelve protestante?: Las políticas del crecimiento evangélico. Cayambe: Abya-Yala.

Tarducci, Mónica (2005). "'Sólo respondo a Dios': el precario liderazgo de las pastoras pentecostales". Revista de Antropología Iberoamericana (AIBR), 40, pp.121.

Teenekes, Hans (1985). El movimiento pentecostal en la sociedad chilena. Iquique: Sub-facultad de Antropología Cultural de la Universidad Libre de Ámsterdam Centro de Investigaciones de la Realidad del Norte (Chile).

Vallverdú, Jaume (2005). "Violencia religiosa y conflicto en Chiapas, México". Nueva Antropología, 65, pp. 55-74.

Wright, Pablo (1992). "La política de la muerte. Discurso shamánico y evangélico de Ios Toba en Argentina". En Cipolletti, M. y Langdon, E. (coords). La muerte y el más allá en las cultura indígenas latinoamericanas. Cayambe: Abya-Yala, pp. 43-60.

Wynarczyk, Hilario (2003). "Los evangélicos en la sociedad argentina, la libertad de cultos y la igualdad. Dilemas de una modernidad tardía". En Bosca, Roberto (ed.). La libertad religiosa en la Argentina. Aportes para una legislación. Buenos Aires: CALIR (Consejo Argentino para la Libertad Religiosa) / Fundación Konrad Adenauer. (2006). "Partidos políticos evangélicos conservadores bíblicos en la Argentina. Formación y ocaso 1991-2001". Civitas (Revista de Ciencias Sociais), 6 (2), pp. 11-41. 